\title{
PENANAMAN NILAI-NILAI ISLAM BERUPA INTEGRASI AL-QURAN DALAM PENGAJARAN ILMU KAUNIYAH MELALUI RPP
}

\author{
Amalia Nurjannah \\ Sekolah Tinggi Ilmu Tarbiyah Raudhatul Ulum Sakatiga \\ Email: amaliahnurjannah1984@gmail.com
}

\begin{abstract}
Abstrak
The aim of planting the islamic values is to realize generation with noble caracter that has strong faith and knowledge. Integrating Islam with the studies in kauniyah is an idea that is based on the assumption that the development of the studies in kauniyah in the Islamic context is a necessity for the continuation of human civilization harmony in the future. Integration of Al-Quran in the teaching of the studies in kauniyah through the lesson plan is one way to implanting the islamic values in students. The way that is done is also prepared lesson plan of the studies in kauniyah developed by integrating the verses of the Al-Quran that are relevant to the material being taught.
\end{abstract}

Key word: value of islamic, intgerating Al-Quran, teaching of the studies in kauniyah, The lesson plan

\section{Pendahuluan}

Memadukan islam dengan ilmu-ilmu kauniyah adalah satu pemikiran yang didasarkan pada asumsi bahwa pengembangan ilmu-ilmu kauniyah dalam konteks keislaman merupakan suatu keharusan bagi kelanjutan peradaban umat manusia yang harmonis di masa depan. Al-Qur'an merupakan petunjuk rabbani yang universal mempunyai kedudukan penting dalam kehidupan manusia di alam dunia ini. Didalamnya telah termaktub aturan-aturan, baik dalam hal ibadah, maupun dalam bidang muamalah (Nasution:2006).

Kepastian kebenaran ilmu-ilmu Al-Quran tidak dapat ditandingi, karena ilmu-ilmu itu berupa hukum-hukum yang langsung diturunkan dari Allah Swt. Sedangkan ilmuilmu kauniah kebenarannya ditentukan oleh hasil analisis akal manusia. Dengan demikian, kebenaran ilmu-ilmu kauniyah harus melalui proses penalaran otak manusia, dan itulah sebabnya harus merujuk kepada Al-Quran diselaraskan dengan hukumhukum dari Allah Swt.

Berdasarkan pada pasal 1 ayat 1 UU No. 20 Tahun 2003 tentang sistem pendidikan nasional menyebutkan bahwa penyelenggaraan pendidikan nasional didasarkan pada orientasi dimensi nilai spiritual keagamaan, akar budaya nasional, responsif terhadap tuntutan dan tantangan perubahan jaman yang berkembang demikian cepat. Ketentuan lain yang terdapat dalam Pasal 3 yang menyebutkan bahwa Pendidikan nasional berfungsi mengembangkan kemampuan dan membentuk watak serta peradaban bangsa yang bermartabat dalam rangka mencerdaskan kehidupan bangsa, bertujuan untuk 


\section{Penanaman Nilai-Nilai Islam Berupa Integritas al-Qur'an dalam Pengajaran Ilmu Kauniyah Melalui RPP \\ Amaliah Nurjannah}

berkembangnya potensi peserta didik agar menjadi manusia yang beriman dan bertakwa kepada Tuhan Yang Maha Esa, berakhlak mulia, sehat, berilmu, cakap, kreatif, mandiri, dan menjadi warga negara yang demokratis serta bertanggung jawab. Supaya fungsi dan tujuan pendidikan nasional tersebut dapat dicapai, penyelenggaraan pendidikan harus dilaksanakan secara sistematis. Penyelenggaraan pendidikan ini tentu akan berkaitan dengan seperangkat acuan nilai dan norma yang dijadikan pegangan oleh masyarakat khususnyaberkaitan dengan penanaman nilai religius siswa.

Lembaga pendidikan mempunyai peranan penting dalam membentuk kepribadian dan tingkah laku moral anak. Penanaman nilai religius dalam diri siswa semua komponen harus dilibatkan, termasuk komponen-komponen pendidikan itu sendiri, yaitu isi kurikulum, proses pembelajaran dan penilaian, pelaksanaan aktivitas atau kegiatan ko-kurikuler, dan seluruh warga dan lingkungan sekolah. Proses pembelajaran akan berjalan dengan baik jika dilaksanakan dengan perencanaan yang baik. Untuk kelancaran pelaksanaan proses pembelajaran ini guru harus mempersiapkan Rencana Pelaksanaan Pembelajaran sebelum mengajar.

Rencana Pelaksanaan Pembelajaran (RPP) adalahrencana yang menggambarkan prosedur dan menajemen pembelajaran untuk mencapai satu atau lebih kompetensi dasar yang telah dijabarkan dalam silabus. RPP ini dapat digunakan oleh setiap pengajar sebagai pedoman umum untuk melaksanakan pembelajaran kepada peserta didiknya, karena di dalamnya berisi petunjuk secara rinci, pertemuan demi pertemuan, mengenai tujuan, ruang lingkup materi yang harus diajarkan, kegiatan belajar mengajar, media, dan evaluasi yang harus digunakan. Berdasarkan pemikiran itulah penulis berusaha mengintegrasikan Al-Quran dalam pengajaran ilmu kauniah melalui Rencana Pelaksanaan Pembelajaran (RPP).

Integrasi ayat al-Quran dalam pengajaran ilmu kauniyah ke dalam Rencana Pelaksanaan Pembelajaran dapat dilakukan pada setiap mata pelajaran. Materi pembelajaran yang berkaitan dengan norma atau nilai-nilai pada setiap mata pelajaran perlu dikembangkan dan dikaitkan dengan ayat-ayat Al-Quran untuk menanamkan nilai-nilai religius dalam diri siswa. Oleh karena itu, penulis melakukan pengintegrasian ayat-ayat Al-Quran dalam pengajaran ilmu-ilmu kauniah melalui proses pembelajaran secara langsung di kelas melalui Rencana Pelaksanaan Pembelajaran. Dengan adanya integrasi ini secara langsung atau tidak langsung siswa dapat memperoleh dan menerima pembelajaran yang harapannya dapat membentuk pribadi yang memiliki nilai-nilai religius.

\section{Penanaman Nilai-Nilai Islam}

Penanaman menurut Kamus Besar Bahasa Indonesia artinya proses, cara, perbuatan menanam, menanami atau menanamkan (Depdiknas KBBI, 2008). Penanaman diartikan sebagai cara/proses atau suatu kegiatan atau perbuatan menanamkan sesuatu pada tempat yang semestinya (dalam hal ini mengenai niai-nilai agama Islam yang berupa nilai keimanan, nilai ibadah dan nilai akhlak pada diri seseorang agar terbentuk pribadi muslim yang Islami) (Pusat Pembinaan dan Pengembangan Bahasa, 1998). 
P-ISSN : 2541-3686

Williams (Macionis, 1970) mengemukakan bahwa nilai merupakan: “...what is desirable, good or bad, beautiful or ugly".Sedang Light, Keller, \& Calhoun (1989) memberikan batasan nilai sebagai berikut: "Value is general idea that people share about what is good or bad, desirable or undesirable. Value transcend any one particular situation....Value people hold tend to color their overall way of life". (Nilai merupakan gagasan umum orang-orang, yang berbicara seputar apa yang baik atau buruk, yang diharapkan atau yang tidak diharapkan. Nilai mewarnai pikiran seseorang dalam situasi tertentu . .... Nilai yang dianut cenderung mewarnai keseluruhan cara hidup mereka).

Menurut Darajat (1984), mendefinisikan nilai adalah suatu perangkatkeyakinan atau perasaan yang diyakini sebagai suatu identitas yang memberikan corak yang khusus kepada pola pemikiran dan perasaan, keterikatan maupun perilaku. Mulyana (2004) mendefinisikan pendidikan nilai sebagai bantuan terhadap peserta didik agar menyadaridan mengalami nilai-nilai serta menempatkannya secara integral dalam keseluruhan hidupnya. Sumaatmadja (2005) menambahkan bahwa pendidikan nilai ialah upaya mewujudkan manusia seutuhnya yaitu manusia yang beriman dan bertaqwa kepada Tuhan Yang Maha Esa, berakhlak mulia, manusiawi dan berkepedulian terhadap kebutuhan serta kepentingan orang lain; yang intinya menjadi manusia yang terdidik baik terdidik dalam imannya, ilmunya maupun akhlaknya serta menjadi warga negara dan dunia yang baik (well educated men and good citenship).Dengan demikian, dapat disimpulkan bahwa nilai adalah sesuatu perasaan yang diyakini kebenarannya yang dapat dijadikan panduan individu dalam memandang sesuatu tentang baik, buruk, bernilai atau tidak bernilai.

Luasnya materi ajaran agama Islam haruslah dipahami oleh seorangmukmin yang ingin mengamalkan ajaran Islam secara kaffah, akan tetapi dari kesemuanya itu yang juga penting untuk diketahui adalah pemahaman tentang nilai-nilai atau unsur-unsur yang terkandung dalam agama Islam. Dimensi kehidupan yang mengandung nilai-nilai ideal Islam dapat dibedakan menjadi 3 kategori (Arifin, 1993), yaitu: dimensi yang mengandung nilai yang meningkatkan kesejahteraan hidup manusia didunia, dimensi yang mengandung nilai yang mendorong manusia untuk meraihkehidupan di akhirat yang membahagiakan, dan dimensi yang mengandung nilai yang dapat memadukan antarakepentingan hidup duniawi dan ukhrawi. Sehingga berdasarkan dimensi-dimensi ini keseimbangan dan keselarasan hidup duniawi ukhrawi menjadi landasan ideal yang harus dikembangkan dalam diri siswa.

Ditinjau dari sumbernya, nilai-nilai islam digolongkan menjadi dua macam, yaitu nilai ilahi dan nilai insani. Nilai ilahi adalah nilai yang bersumber dari Al-Qur'an dan hadits. Nilai ilahi dalam aspek teologi (kaidah keimanan) tidak akan pernahmengalami perubahan, dan tidak berkecenderungan untuk berubah ataumengikuti selera hawa nafsu manusia. Sedangkan aspek alamiahnya dapatmengalami perubahan sesuai dengan zaman dan lingkungannnya. Sedangkan nilai insani adalah nilai yang tumbuh dan berkembang atas kesepakatan manusia. Nilai insani ini akan terus berkembang ke arah yanglebih maju dan lebih tinggi. Nilai ini bersumber dari ra'yu, adat istiadatdan kenyataan alam (Muhaimin, 1991). Sejalan dengan nilai-nilai islam ini, Menurut Rahman 
Penanaman Nilai-Nilai Islam Berupa Integritas al-Qur'an dalam Pengajaran Ilmu Kauniyah Melalui RPP

Amaliah Nurjannah

Saleh (Zulkarnain, 2008) nilai dasar dalam islam disebut sebagai nilai dasar ubudiyah, moralitas/akhlaqur karimah, dan nilai dasar inizhamiyah/kedisiplinan. Nilai dasar ubudiyah meliputi aktivitas manusia sebagai hamba Allah Swt dan selaku khafilah-Nya di muka bumi, hakikatnya ber-bakti atau mengabdi kepada Allah sekaligus untuk mendapatkan ridha-Nya (QS. Az-Zari-yat: 56), yang artinya: "Dan Aku tidak men-ciptakan jin dan manusia melainkan untuk menyembah $\mathrm{Aku}$ ". Nilai dasar moralitas/akhlaqul karimah merupakan inti ajaran Islam yang dibawa oleh Rasulullah SAW, yang tidak lain untuk membentuk akhlak manusia menjadi mulia.

Sehingga berdasarkan uraian diatas penanaman nilai-nilai agama merupakan suatu tindakan atau cara untuk menanamkan pengetahuan yang berharga berupa nilai ubudiyah dan akhlaqul karimah yang belandaskan pada wahyu Allah SWT dengan tujuan agar anak mampu mengamalkan pengetahuannya dalam kehidupan sehari-hari dengan baik dan benar dengan kesadaran tanpa paksaan.

\section{Al-Quran}

Menurut al-Lihyani, kata al-Qur"an berasal dari kata qara "a yaqra "u qira "atan yang berarti membaca dan mengikuti pola kata al-rujhan dan al-gufran. Menurut Ali ashShabuni sepertiyang dikutip oleh Mashuri Sirojuddin Iqbal dan Ahmad Fudloli Al-Quran adalah kalamullah (firman Allah) yang mengandung mukjizat yang diturunkan kepada penutup para nabi dan rasul, dengan perantaraan yang dapat dipercaya yaitu malaikat Jibril, yang ditulis dalam mushaf dan diriwayatkan kepada kita secara mutawwatir, serta diperintahkan membacanya, diawali dengan surat al-Fatihah(1) dan diakhiri dengan surat an-Nas(114) (Iqbal, 1989).Sedangkan menurut Hasbi As-Siddiqi yaitu wahyu yang diterima oleh malaikat Jibril dan disampaikan kepada penutup para nabi dan rasul Muhammad Saw. yang tak dapat ditandingi oleh siapapun, yang diturunkan berangsurangsur lafal dan maknanya, yang dinukilkan dari Muhammad Saw. kepada kita untuk umatnya dengan jalan mutawwatir, dan tertera dengan sempurna dalam mushaf baik lafal maupun maknanya, sedang yang membacanya diberi pahala, karena membaca al-Qur "e an dihukumkan suatu ibadah (As-Siddiqi, 1971).

Al-Qur'an lengkap dengan segala petunjuk yang meliputi seluruh aspek kehidupan dan bersifat universal, sudah barang tentu dasar pendidikan umat Islam adalah bersumber kepada filsafat hidup yang berdasarkan kepada Al-Qur'an. Kedudukan AlQur'an sebagai sumber pokok pendidikan Islam dapat dipahami dari ayat Al-Qur'an itu sendiri. Firman Allah:

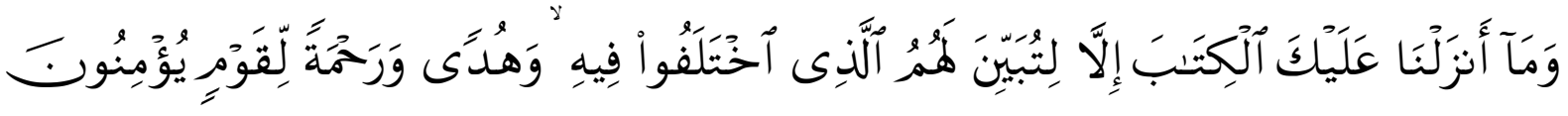


RAUDHAH Proud To Be Professionals gurnal Tarbiyakndlamiyak

Volume 1 Nomor 1 Edisi Juni 2016

P-ISSN : 2541-3686

Artinya: Dan Kami tidak menurunkan kepadamu Al-Kitab (Al Quran) ini, melainkan agar kamu dapat menjelaskan kepada mereka apa yang mereka perselisihkan itu dan menjadi petunjuk dan rahmat bagi kaum yang beriman. (Qs. An-Nahl : 64).

Dan firman Allah dalam

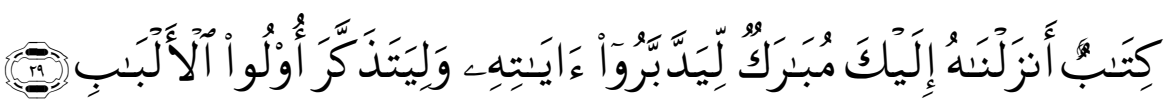

Artinya: Ini adalah sebuah kitab yang Kami turunkan kepadamu penuh dengan berkah supaya mereka memperhatikan ayat-ayatNya dan supaya mendapat pelajaran orang-orang yang mempunyai fikiran. (Qs. As-Shad : 29).

Prinsip menjadikan Al-Quran sebagai dasar penanaman nilai-nilai islam bukan hanya dipandang sebagai kebenaran keyakinan semata. Lebih jauh kebenaran itu juga sejalan dengan kebenaran yang dapat diterima oleh akal yang sehat dan bukti sejarah. Firman Allah dalam Qs. Al-Baqarah : 2

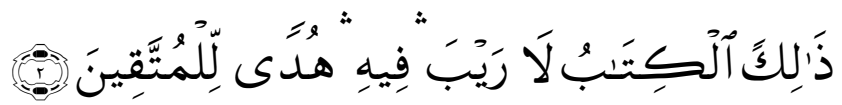

Artinya : Kitab (Al Quran) ini tidak ada keraguan padanya; petunjuk bagi mereka yang bertaqwa. (Qs. Al-Baqarah : 2).

\section{Ilmu Kauniyah}

Ilmu merupakan padanan kata bahasa Inggris science, atau scientia (bahasa Latin). Kata kerja bahasa Latin adalah scire, yang artinya tahu atau mengetahui. Kata ilmu berasal dari bahasa Arab 'ilm ('alima-ya'lamu-'ilm), yang berarti pengetahuan (al-ma'rifah) (Munawwir, 1984). Jhon G. Kemeny mendefinisikan ilmu sebagai berikut: all knowledges collected by means of the scientific method (semua pengetahuan yang dikumpulkan dengan metode ilmiah). Dalam perspektif islam ilmu merupakan pengetahuan mendalam hasil usaha yang sungguh-sungguh (ijtihad) dari para ilmuan muslim ("ulama/mujtahid) atas persoalan-persoalan duniawi dan ukhrawi dengan bersumber kepada wahyu Allah (Azizi, 2003).

Ilmu menempati posisi yang penting dalam pandangan islam karena merupakan bukti nyata usaha manusia dalam menggunakan akalnya. Ilmu dapat membawa manusia kepada penghayatan terhadap kekuasaan Allah yang tak terbatas, dan sekaligus menyadarkannya akan posisinya yang sangat terbatas. Karena itu, posisi orang yang berilmu dihargai beberapa derajat, sebagaimana diungkapkan Alquran:
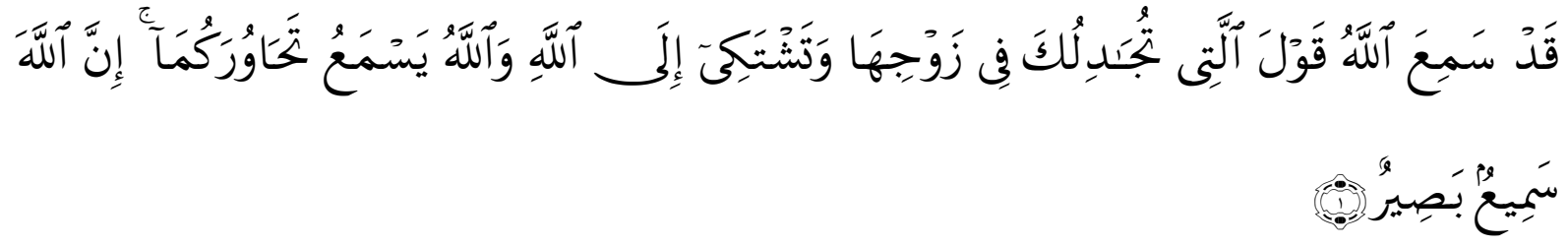
Penanaman Nilai-Nilai Islam Berupa Integritas al-Qur'an dalam Pengajaran Ilmu Kauniyah Melalui RPP

Amaliah Nurjannah

Artinya: ... Niscaya Allah akan meninggikan orang-orang yang beriman di antaramu dan orangorang yang diberi ilmu pengetahuan beberapa derajat. dan Allah Maha mengetahui apa yang kamu kerjakan. (Qs. Al-Mujadillah: 11).

Ilmu yang dikembangkan pada prinsipnya adalah ilmu yang bermanfaat bagi kehidupan manusia yang meliputi ilmu tanziliyah dan ilmu kauniyah. Dilihat dari fungsinya ilmu tanziliyah sebagai pedoman hidup (manhaj al-hayah), sedangkan ilmu kauniyah berfungsi sebagai sarana kehidupan (wasail al-hayah) (Hidayatulloh, 2013). Ilmu-ilmu Tanziliyah yaitu ilmu-ilmu Allah yang diturunkan langsung lewat wahyu; baik yang berupa Kalamullah, Al-Qur'an (Al-Kitab) ataupun yang berupa penjelasan dan contoh langsung dari Rasulullah atau Al-Hadits, As-Sunnah, As-Siroh (Al-Hikmah). Bersumber dari ilmu ini kemudian muncul ilmu-ilmu hasil ijtihad Ulama, seperti Tafsir, Ilmu Tafsir, Mustholahul Hadits, Ilmu Kalam, Ilmu ‘Aqoid, Ilmu Fiqih, Ushul Fiqih, Ilmu Akhlaq, Ilmu Tashawwuf dll. Ilmu-ilmu tersebut diajarkan oleh Rasulullah sebagai implementasi dari tugas "Yu'allimuhum al-Kitab wal-Hikmah".Ilmu-ilmu Kauniyah yaitu ilmu-ilmu Allah yang berhubungan dengan alam semesta dan kehidupan sehari-hari yang dihamparkan oleh Allah dan ditampakkan langsung kepada manusia. Secara garis besar, ilmu-ilmu ini ada 3 jenis, yaitu (1) Ilmu Pengetahuan Alam, seperti Fisika, Biologi, Fauna, Flora, Kimia, Astronomi, dan Ilmu-ilmu tentang bumi seperti Geografi, Geologi, Geofisika, Geokimia, Geomorfologi dll. (2) Ilmu Pengetahuan Sosial (Ikhtilafil-Lail wanNahar), seperti Sejarah, Ekonomi, Politik, Hukum, Hankam, Tatanegara, Antropologi, Sosiologi dll. (3) Ilmu Pengetahuan Personalitas (Wa fi anfusikum afala tubshirun) atau ilmu yang berhubungan dengan diri manusia sendiri, seperti Ilmu Faal, Anatomi Tubuh, Psikologi, Karakterologi dll (Nuris, 2005).

Dalam Al-Quran telah dijelaskan bahwa tujuan pengembangan ilmu agar dapat membawa keberkahan dan memberi manfaat yang besar. Sehingga dalam proses pengajaran ilmu baik ilmu tanziliyah maupun ilmu kauniyah tidak boleh keluar dari perintah-perintah yang ada dalam Al-Quran.

\section{Cara Pengintegrasian Al-Quran Melalui RPP}

Berdasarkan UU No. 20 Tahun 2003 Pasal 37 ayat 1 menyebutkan bahwa kurikulum pendidikan dasar dan menengah wajib memuat: (a) pendidikan agama, (b) pendidikan kewarganegaraan, (c) bahasa, (d) matematika, (e) ilmu pengetahuan alam, (f) ilmu pengetahuan sosial, (g) seni dan budaya, (h) pendidikan jasmani dan olahraga, (i) keterampilan/ kejuruan, (j) muatan lokal. Dalam pengembangan kurikulumdilakukan dengan mengacu pada standar nasional pendidikan untuk mewujudkan tujuan pendidikan nasionalsebagaimana terdapat pada UU No. 20 tahun 2003 pasal 36 ayat 1.

Dalam implementasinya, pengembangan kurikulum harus memperhatikan beberapa aspek yaitu: (a) Peningkatan iman dan takwa serta akhlak mulia, (b) Peningkatan potensi, kecerdasan, dan minat sesuai dengantingkat perkembangan dan kemampuan peserta didik, (c) Keragaman potensi dan karakteristik daerah dan lingkungan, (d) Tuntutan pembangunan daerah dan nasional, (e) Tuntutan dunia kerja, 
(f) Perkembangan ilmu pengetahuan, teknologi, dan seni, (g) Agama, (h) Dinamika perkembangan global, (i) Persatuan nasional dan nilai-nilai kebangsaan, (j) Kondisi sosial budaya masyarakat setempat, (k) Kesetaraan jender, (l) Karakteristik satuan pendidikan.

Integrasi Al-Quran untuk menanamkan nilai-nilai islam dan sejalan dengan salah satu prinsip diatas yaitupeningkatan iman dan takwa serta akhlak mulia ke dalam diri siswa tidak hanya melalui ilmu-ilmu tanziliyah saja tetapi dapat terinternalisasi juga ke dalam ilmu-ilmu kauniyah.Cara mengintegrasikan Al-Quran ke dalam ilmu kauniyah melalui RPP adalah menyusun Rencana Pelaksanaan Pembelajaran pada setiap pelajaran dan menyisipkan ayat-ayat Al-Quran yang relevan ke dalam pembahasan materi.

Implementasi pengintegrasian ayat-ayat Al-Quran yang relevan ke dalam ilmuilmu kauniyah dapat dilihat seperti beberapa contoh berikut ini:

Tabel 1.

\section{Ayat-ayat Al-Quran yang Relevan dengan}

\section{Ilmu-ilmu Kauniyah}

\begin{tabular}{|c|c|c|c|}
\hline No & Mata Pelajaran & Materi & $\begin{array}{c}\text { Ayat Al-Quran y } \\
\text { Relevan }\end{array}$ \\
\hline \multirow[t]{8}{*}{1} & Matematika & $\begin{array}{l}\text { Bentuk pangkat, akar, dan } \\
\text { logaritma }\end{array}$ & Q.S Al-Baqarah: 261 \\
\hline & & Pecahan & Q.S An-Nisa: $11-12$ \\
\hline & & $\begin{array}{l}\text { Persamaan kuadrat dan } \\
\text { fungsi kuadrat }\end{array}$ & Q.S Al-An'am: 59 \\
\hline & & $\begin{array}{l}\text { Sistem persamaan linier dan } \\
\text { kuadrat }\end{array}$ & Q.S Ar-Rahman: 33 \\
\hline & & Pertidaksamaan satu variabel & Q.S Ar-Ra'ad: 16 \\
\hline & & Logika & Q.S Al-Hujurat: 6 \\
\hline & & Trigonometri & Q.S Al-baqarah: 149 \\
\hline & & Ruang Dimensi Tiga & Q.S At-Taubah: 18 \\
\hline \multirow{7}{*}{2} & Fisika & Gravitasi alam semesta & Q.S Qaf: 38 \\
\hline & & & Q.S Al-Qori'ah: 1-5 \\
\hline & & Relativitas waktu & Q.S Al-Hajj: 47 \\
\hline & & & Q.S As-Sajadah:5 \\
\hline & & Garis edar & Q.S Al-Anbiya':33 \\
\hline & & & Q.S Yasin:38 \\
\hline & & & Q.S Az-Zariyat:7 \\
\hline
\end{tabular}


Penanaman Nilai-Nilai Islam Berupa Integritas al-Qur'an dalam Pengajaran Ilmu Kauniyah Melalui RPP

Amaliah Nurjannah

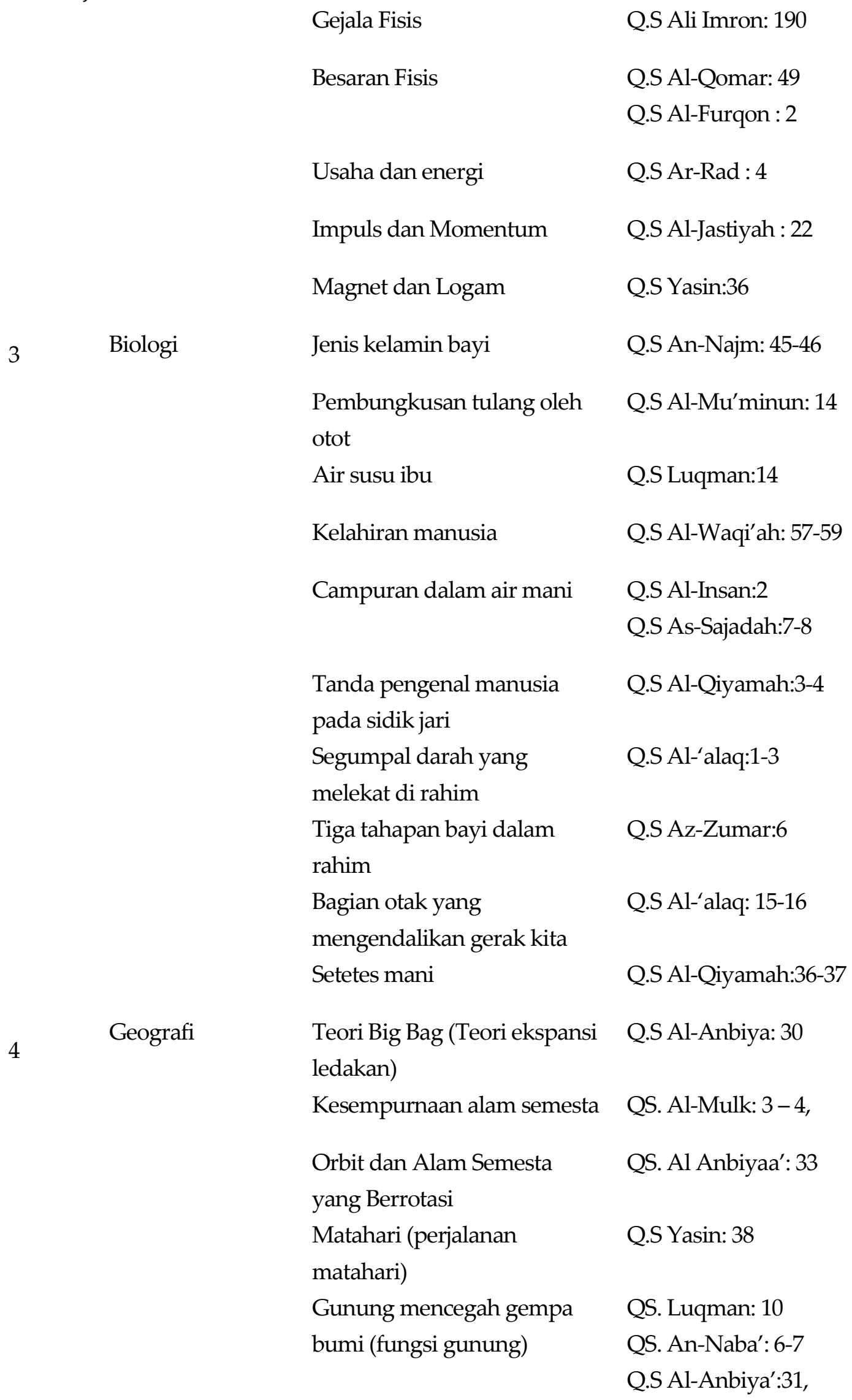


RAUDHAH Proud To Be Professionals qurnal Tarbiyak7slamiyak

Volume 1 Nomor 1 Edisi Juni 2016

P-ISSN : 2541-3686

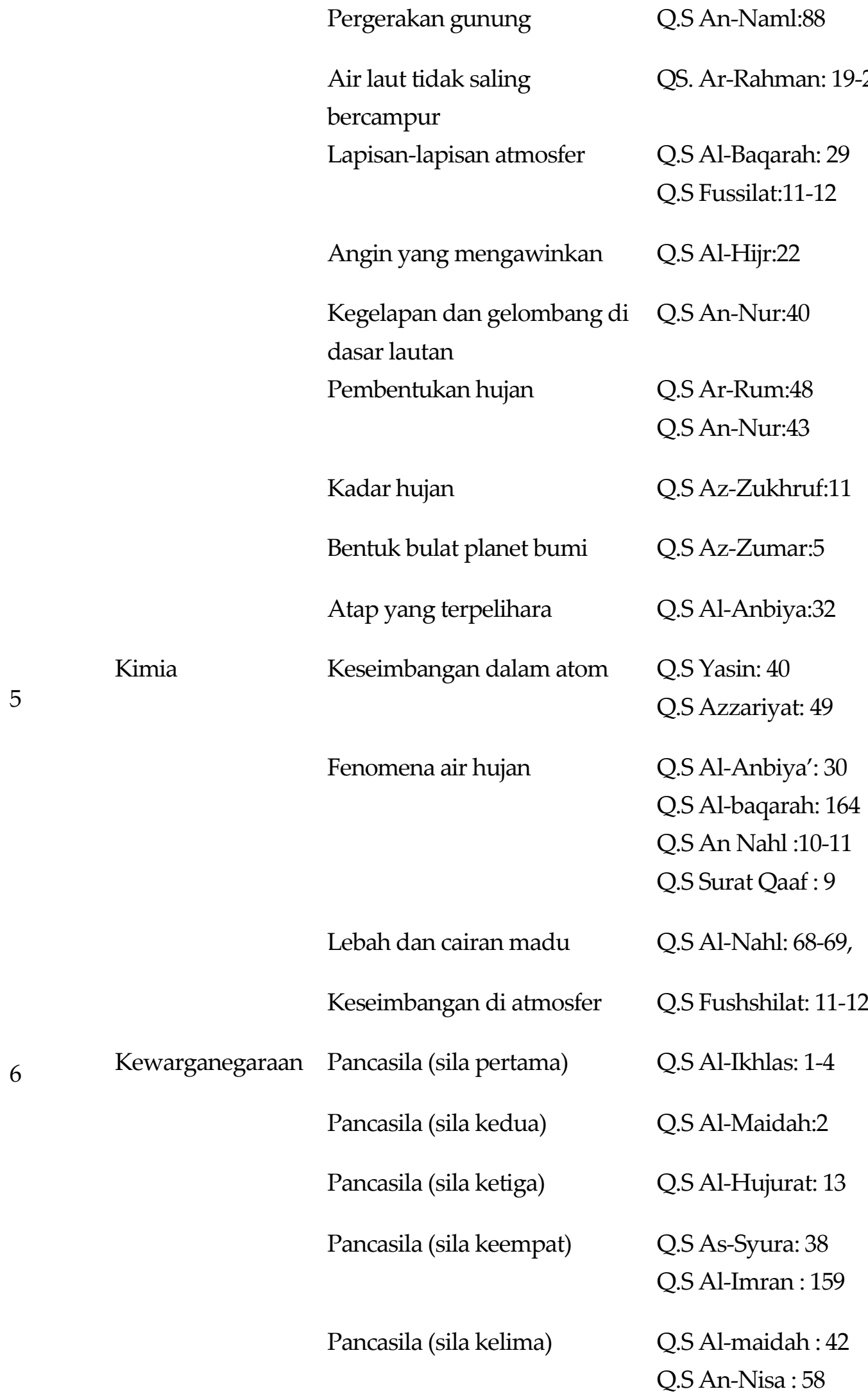

Berdasarkan Tabel 1 diatas, berikut ini salah satu contoh Rencana Pelaksanaan Pembelajaran (RPP) dengan mengintegrasikan ayat Al-Quran ke dalam salah satu mata pelajaran. 
Penanaman Nilai-Nilai Islam Berupa Integritas al-Qur'an dalam Pengajaran Ilmu Kauniyah Melalui RPP

Amaliah Nurjannah

\section{RENCANA PELAKSANAAN PEMBELAJARAN}

$\begin{array}{ll}\text { Nama Sekolah } & : \\ \text { Mata Pelajaran } & : \text { geografi } \\ \text { Kelas / Semster } & : x / \mathbf{i} \\ \text { Tahun Pelajaran } & : \\ \text { Alokasi Waktu } & : 2 \text { jam pelajaran }\end{array}$

\section{Standar Kompetensi :}

2. Memahami Sejarah Pembentukan Muka Bumi

\section{Kompetensi Dasar :}

2.1 Mendeskripsikan Jagad Raya dan Tata Surya

\section{Indikator :}

- Mendeskripsikan pengertian Jagat Raya.

- Mengetahui teori-teori pembentukan tata surya

8 Karakter siswa yang diharapkan :

- Religius, Kerja keras, Jujur, saling menghargai.

8 Kewirausahaan / Ekonomi Kreatif :

- Kerja keras, jujur, saling menghargai orang lain, inovatif,

\section{A. Tujuan Pembelajaran:}

Setelah mempelajari materi ini siswa dapat:

- Mendeskripsikan pengertian Jagat Raya

- Menjelaskan teori-teori pembentukan tata surya

\section{B. Materi Ajar}

Tata surya adalah suatu kelompok benda langit, yaitu matahari dan planet-planet yang terdiri dari Merkurius, Venus, Bumi, Mars, Yupiter, Saturnus, Uranus, Neptunus beserta 165 buah satelit planet yang sudah diketahui sampai sekarang, serta objek-objek tata surya lainnya, seperti asteroid, meteorit, planet katai dan komet yang bergerak mengikuti dinamika Newton.

Pembentukan Tata Surya 
P-ISSN : 2541-3686

Pertanyaan manusia mengenai asal usul benda langit yang bergerak teratur di langit memunculkan beberapa teori pembentukan tata surya, antara lain

a. Teori Kabut atau Teori Nebula oleh Immanuel Kant (1724-1804) dan Pierre Simon de Laplace (1749-1827)

Mereka menyatakan tata surya berasal dari sebuah awan gas raksasa yang mengerut sambil berputar akibat gaya gravitasi. Saat mengerut, kecepatan rotasinya semakin bertambah sehingga bentuknya yang seperti bola berubah manjadi piringan yang terus berputar. Karena terus berputar, ada bagian-bagian piringan ini yang terlempar keluar, memadat, lalu menjadi planet-planet dan satelitnya.

\section{b.Teori Bintang Kembar}

Hipotesis bintang kembar dikemukakan oleh Fred Hoyle pada tahun 1956. Hipotesis ini menyatakan bahwa pada awalnya tata surya berupa dua bintang yang berukuran hampir sama dan letaknya berdekatan. Dari kedua bintang tersebut, dengan salah satunya belum stabil. Pada bintang yang tidak stabil ini suatu saat terjadi reaksi yang sangat cepat sehingga menghasilkan energi berupa panas, dan akhirnya bintang tersebut meledak menjadi serpihan-serpihan kecil. Serpihan-serpihan tersebut terperangkap oleh gaya gravitasi bintang yang tidak meledak dan mulai bergerak mengelilinginya. Karena adanya gaya gravitasi serpihan yang letaknya berdekatan bergabung sedikit demi sedikit dan akhirnya membentuk planet, dan terbentuklah susunan tata surya.

c. Teori Big Bang

Big Bang (Ledakan Dahsyat atau Dentuman Besar) dalam kosmologi adalah salah satu teori ilmu pengetahuan yang menjelaskan perkembangan dan bentuk awal dari alam semesta. Teori ini menyatakan bahwa alam semesta ini berasal dari kondisi super padat dan panas, yang kemudian mengembang sekitar 13.700 juta tahun lalu.

Para ilmuwan juga percaya bawa Big Bang membentuk sistem tata surya. Konsekuensi alami dari Teori Big Bang yaitu pada masa lampau alam semesta punya suhu yang jauh lebih tinggi dan kerapatan yang jauh lebih tinggi.

Pada tahun 1929 Astronom Amerika Serikat, Edwin Hubble melakukan observasi dan melihat Galaksi yang jauh dan bergerak selalu menjauhi kita dengan kecepatan yang tinggi. Ia juga melihat jarak antara Galaksi-galaksi bertambah setiap saat. Penemuan Hubble ini menunjukkan bahwa Alam Semesta kita tidaklah statis seperti yang dipercaya sejak lama, namun bergerak mengembang.

Pada saat itu dimana Alam Semesta memiliki ukuran nyaris nol, dan berada pada kerapatan dan panas tak terhingga; kemudian meledak dan mengembang dengan laju pengembangan yang kritis, yang tidak terlalu lambat untuk membuatnya segera mengerut, atau terlalu cepat sehingga membuatnya menjadi kurang lebih kosong. Dan sesudah itu, kurang lebih jutaan tahun berikutnya, Alam Semesta akan terus mengembang tanpa kejadian-kejadian lain apapun. Alam Semesta secara keseluruhan akan terus mengembang dan mendingin. 


\section{Penanaman Nilai-Nilai Islam Berupa Integritas al-Qur'an dalam Pengajaran Ilmu Kauniyah Melalui RPP}

\section{Amaliah Nurjannah}

Selain berdasarkan fakta ilmiah, sebenarnya dari sisi religi (keagamaan) pernyataan teori "Big Bang" ini termuat dalam kitab-kitab suci seperti Taurat, Injil dan Al Qur'an. Pembentukan alam semesta dari “ketiadaan” diberitakan di dalam Al Qur'an:

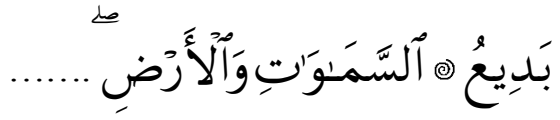

"Dia Pencipta langit dan bumi...." (QS. Al An'am: 101)

Salah satu kebenaran lain yang terungkap dalam Al Qur'an adalah pengembangan jagat raya yang ditemukan pada akhir tahun 1920-an. Penemuan Hubble tentang pergeseran merah dalam spektrum cahaya bintang diungkapkan dalam Al Qur'an. Singkatnya, temuan-temuan ilmu alam modern mendukung kebenaran yang dinyatakan dalam Al Qur'an dan bukan dogma materialis. Materialis boleh saja menyatakan bahwa semua itu "Kebetulan", namun fakta yang jelas adalah bahwa alam semesta terjadi sebagai hasil penciptaan dari pihak Allah dan satu-satunya pengetahuan yang benar tentang asal mula alam semesta ditemukan dalam firman Allah yang diturunkan kepada kita.

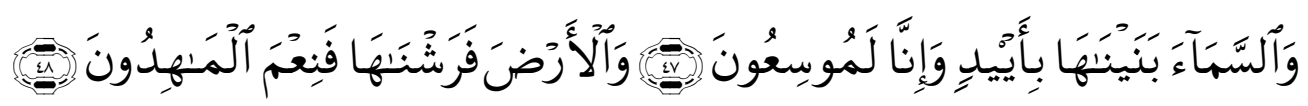

"Dan langit itu kami bangun dengan kekuasaan (kami) dan Sesungguhnya kami benar-benar berkuasa. "Dan bumi itu kami hamparkan, Maka sebaik-baik yang menghamparkan (adalah Kami)."(QS. Adz Dzariyaat: 47-48)

Teori mengenai terciptanya alam semesta (Big Bang), disebutkan bahwa alam semesta tercipta dari sebuah ledakan kosmis 10-20 milyar tahun yang lalu mengakibatkan adanya ekspansi (pengembangan) alam semesta. Sebelum terjadinya ledakan kosmis tersebut, seluruh ruang materi dan energi terkumpul dalam sebuah titik. Sekarang, mungkin ada di antara kita ingin tahu bagaimana Al Qur'an menjelaskan tentang terbentuknya alam semesta ini. Firman Allah Swt:
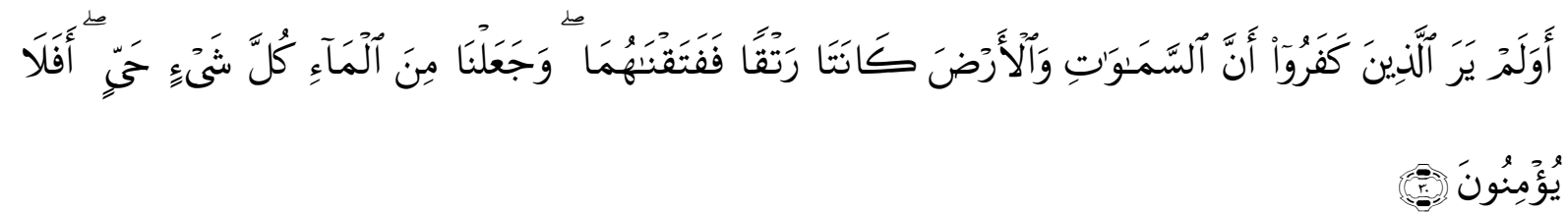

"Dan apakah orang-orang yang kafir tidak mengetahui bahwasanya langit dan bumi itu keduanya dahulu adalah suatu yang padu, Kemudian kami pisahkan antara keduanya. dan dari air kami jadikan segala sesuatu yang hidup. Maka mengapakah mereka tiada juga beriman? (QS. Al Anbiyaa': 30)

Berdasarkan terjemahan dan tafsir Bachtiar Surin ditafsirkannya bahwa matahari adalah benda angkasa yang menyala-nyala yang telah berputar berkeliling sumbunya sejak berjuta-juta tahun. Dalam proses perputarannya dengan kecepatan tinggi itu, maka 
P-ISSN : 2541-3686

terpelantinglah bongkahan-bongkahan yang akhirnya menjadi bumi dan beberapa benda angkasa lainnya dari bongkahan matahari itu. Masing-masing beredar menurut garis tengah lingkaran matahari, semakin lama semakin bertambah jauh juga, hingga masingmasing menempati garis edarnya yang sekarang. Dan seterusnya akan tetap beredar dengan teratur sampai batas waktu yang hanya diketahui Allah Swt.

Teori ledakan dahsyat (Big Bang) juga mengatakan adanya pemuaian alam semesta secara terus menerus dengan kecepatan dahsyat yang diumpamakan mengembangnya permukaan balon yang sedang ditiup, yang mengisyaratkan bahwa galaksi akan hancur kembali. Isyarat ini sudah dijelaskan dalam Al Qur'an:

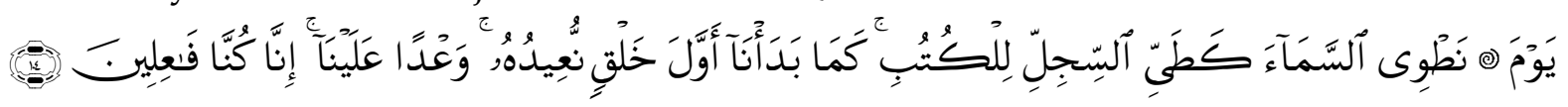

"Pada hari kami gulung langit sebagai menggulung lembaran - lembaran kertas. sebagaimana kami Telah memulai penciptaan pertama begitulah kami akan mengulanginya. Itulah suatu janji yang pasti kami tepati; Sesungguhnya kamilah yang akan melaksanakannya."

(QS. Al Anbiyaa': 104)

\section{d. Hipotesis Planetisimal}

Hipotesis planetisimal pertama kali dikemukakan oleh Thomas C. Chamberlain (1843-1928) dan Forest R. Moulton (1872-1928), keduanya berasal dari Amerika. Menurut Hipotesis planetisimal(berarti planet kecil) matahari telah ada sebagai salah satu dari bintang-bintang yang banyak. Pada suatu masa, ada bintang yang berpapasan pada jarak yang tidak terlalu jauh. Akibatnya, terjadilah peristiwa pasang naik pada permukaan matahari maupun bintang itu. Sebagian dari masa matahari itu tertarik ke arah bntang. Menurut Moulton dan Chamberlin. pada waktu bintang menjauh, sebagian dari massa matahari itu jatuh kembali ke permukaan matahari dan sebagian lagi terhambur ke ruang angkasa sekitar matahari. Hal inilah yang dinamakan planetesimal yang kemudian menjadi planet-planet dan beredar pada orbitnya.

\section{e. Teori Komet Buffon}

Tahun 1745, George comte Buffon dari Prancis mengenalkan teori dualistik dan katastrofi yang menyatakan bahwa tabrakan komet dengan permukaan matahari menyebabkan materi matahari terlontar dan membentuk planet pada jarak yang berbeda-beda. kelemahannya Buffon tidak bisa menjelaskan asal komet. Ia hanya mengasumsi bahwa komet jauh lebih masif dari kenyataannya.

\section{f. Teori Awan Debu}

Pada tahun 1940, seorang ahli astronomi Jerman, Carl Von Weizsaeker mengembangkan suatu teori awan debu (The Dust-Cloud Theory). Teori ini kemudian disempurnakan lagi oleh ahli astronomi lain, yaitu Gerard P. Kuiper (1950), Subrahmanyan Chandrasekhar, dan lain-lain. Pada dasarnya terori ini mengemukakan, bahwa tata surya itu terbentuk dari gumpalan awan gas dan debu. Dewasa ini alam 
Penanaman Nilai-Nilai Islam Berupa Integritas al-Qur'an dalam Pengajaran Ilmu Kauniyah Melalui RPP

Amaliah Nurjannah

semesta bertebaran pebggumpalan awan seperti itu. Lebih dari lima ribu juta tahun yang lalu, salah satu gumpalan itu mengalami pemampatan. Pada proses pemampatan itu partikel-partikel debu tertyarik ke bagian pusat awan itu, membentuk gumpalan bola yang mulai berpilin. Lama-kelamaan gumpalan gas itu memipih membentuk cakram yang tebal dibagian tengah dan lebih tipis di tepinya. Bagian tengah cakram gas itu berpilin lebih lambat daripada bagian tepinya, partikel-partikel dibagian tengah cakram itu kemudian saling menekan, sehingga menimbulakan panas dan menadi pijar. Bagian inilah yang kemudian menjdai matahari. Bagian yang lebih luar berpusing sangat cepat, sehingga terpecah-pecah menjadi banyak gumpalan gas dan debu yang lebih kecil. Gumpalan kecil ini berpilin pula. Bagian inilah kemudian membeku dan menjadi planetplanet-planet serta satelit satelitnya.

\section{Metode Pengajaran}

Ceramah, Observasi, Diskusi, Studi Pustaka

\section{Sumber/ Bahan/ Alat Belajar}

- Buku sumber Geografi SMA

- Buku-buku penunjang yang relevan

- OHP / Slide Proyektor

- Gambar proses pembentukan Jagat Raya

- Internet

Strategi Pembelajaran

\begin{tabular}{|c|c|c|}
\hline Tatap Muka & Terstruktur & Mandiri \\
\hline $\begin{array}{l}\text { - Memahami sejarah } \\
\text { pembentukan bumi }\end{array}$ & $\begin{array}{l}\text { - Carilah pengertian dan } \\
\text { proses terjadinya Jagat } \\
\text { Raya dari situs internet! }\end{array}$ & $\begin{array}{l}\text { - Siswa dapat Secara kelompok, } \\
\text { mendiskusikan tentang } \\
\text { pandangan manusia } \\
\text { mengenai Jagat Raya }\end{array}$ \\
\hline
\end{tabular}

\section{E. Langkah-langkah Kegiatan Pembelajaran}

1. Kegiatan Pendahuluan

- Apersepsi: Mengkaitkan materi terbentuknya jagat raya dengan galaksi dan tata surya.

- Guru menanyakan tentang benda-benda langit yang ada di Jagat Raya.

2. Kegiatan Inti

\section{Eksplorasi}

Dalam kegiatan eksplorasi, guru: 
- Guru menjelaskan pengertian, proses terjadinya, dan pandangan manusia mengenai Jagat Raya secara garis besar. (nilai yang ditanamkan: Kerja keras, Jujur, saling menghargai.);

- Guru menjelaskan proses terjadinya jagat raya dengan mengintegrasikan ayat Al-Quran yaitu menjelaskan dengan mengkaji proses terbentuknya berdasarkan bukti-bukti dalam Al-Quran.

(nilai yang ditanamkan: religius)

\section{Elaborasi}

Dalam kegiatan elaborasi, guru:

- Penugasan secara kelompok, siswa mencari proses terjadinya Jagat Raya dan pandangan manusia mengenai Jagat Raya dari situs internet(nilai yang ditanamkan: Kerja keras, Jujur, saling menghargai.);

- Tanya-jawab berdasarkan hasil temuan siswa (nilai yang ditanamkan: Kerja keras, Jujur, saling menghargai.);

\section{Konfirmasi}

Dalam kegiatan konfirmasi, Siswa:

- Menyimpulkan tentang hal-hal yang belum diketahui(nilai yang ditanamkan: Kerja keras, Jujur, saling menghargai.);

- Menjelaskan tentang hal-hal yang belum diketahui.(nilai yang ditanamkan: Kerja keras, Jujur, saling menghargai.)

3. Kegiatan Penutup

- Guru memberikan kesempatan kepada siswa untuk bertanya mengenai materi yang kurang dimengerti. (nilai yang ditanamkan: Kerja keras, Jujur, saling menghargai.);

- Bersama-sama melakukan refleksi materi yang telah dibahas. (nilai yang ditanamkan: Kerja keras, Jujur, saling menghargai.);

\section{F. Penilaian}

\section{Penilaian Kognitif}

A. Bentuk instrumen: Essay

B. Soal:

1. Jelaskanlah perbedaan teori Nebula dengan teori Planetesimal tentang terbentuknya tata Surya!

2. Jelaskanlah teori Big Bang dalam pembentukan alam semesta! 
Penanaman Nilai-Nilai Islam Berupa Integritas al-Qur'an dalam Pengajaran Ilmu Kauniyah Melalui RPP

Amaliah Nurjannah

\section{Penilaian Afektif}

Lembar Penilaian Afektif

\begin{tabular}{|c|c|c|c|c|c|c|}
\hline \multirow[b]{2}{*}{ No } & \multirow{2}{*}{$\begin{array}{l}\text { Nama } \\
\text { siswa }\end{array}$} & \multicolumn{4}{|l|}{ Indikator } & \multirow{2}{*}{$\begin{array}{l}\text { Jumlah } \\
\text { nilai }\end{array}$} \\
\hline & & Perhatian & Toleransi & $\begin{array}{l}\text { Tanggung } \\
\text { Jawab }\end{array}$ & Keterampilan & \\
\hline
\end{tabular}

Keterangan:

4 : sangat santun dan bertanggung jawab

3: santun dan bertanggung jawab

2: kurang santun dan kurang bertanggung jawab

1: tidak santun dan tidak bertanggung jawab

\begin{tabular}{|l|l|l|}
\hline Skor & Kelas interval & Nilai \\
\hline $15-16$ & $90-100$ & A (sangat baik) \\
\hline $13-14$ & $80-89$ & B (baik) \\
\hline $11-12$ & $70-79$ & C (cukup) \\
\hline $9-10$ & $60-69$ & D (kurang) \\
\hline
\end{tabular}

Mengetahui,

Kepala Sekolah....

Guru Geografi

NIP/NIK.

NIP/NIK. 


\section{Simpulan}

Penanaman nilai-nilai islam berupa integrasi ayat-ayat Al-Quran dapat dilakukan pada setiap mata pelajaran baik pada ilmu tanziliyah maupun ilmu kauniyah. Pengintegrasian ayat-ayat Al-Quran dengan menggunakan Rencana Pelaksanaan Pembelajaran kedalam ilmu-ilmu kauniyah adalah sebagai media untuk memudahkan merencanakan pembelajaran yang akan dilaksanakan oleh guru. Dengan adanya pengintegrasian ayat-ayat Al-Quran ke dalam proses pembelajaran maka ayat-ayat AlQuran ini akan menjadi basis terhadap ilmu sehingga siswa tidak hanya memperoleh pengetahuan, tetapi akan menjadikan siswaberakhlak mulia yang kuat iman.

\section{DAFTAR PUSTAKA}

Arifin, M. 1993. Filsafat Pendidikan Islam. Jakarta: Bumi Aksara

As-Siddiqi, H. 1971. Tafsir Al-Bayan. Bandung: Al-Ma"arif.

Azizy, A. 2003. Pengembangan Ilmu-Ilmu Keislaman. Jakarta: Direktorat Perguruan Tinggi Agama Islam Departemen Agama RI.

BSNP. 2006. Panduan Penyusunan Kurikulum Tingkat Satuan Pendidikan Jenjang Pendidikan Dasar dan Menengah. Jakarta: Depdiknas

Darajat, Z. 1984. Dasar-dasar Agama Islam. Jakarta: Bulan Bintang

Depdiknas, 2008, “Kamus Besar Bahasa Indonesia", Gramedia Pustaka Indonesia.

Depdiknas. 2003. Undang-Undang Republik Indonesia No. 20 Tahun 2013 Tentang Sistem Pendidikan Nasional. Jakarta: Depdiknas

Hidayatulloh, F. 2013. Orientasi Pengembangan Ilmu Dalam Perspektif Islam. Tersedia: journals.itb.ac.id/index.php/sostek/article/view/1127. Diakses pada tanggal 1 Oktober 2015

Iqbal, M., Fudlali, A. 1989. Pengantar Ilmu Tafsir.Bandung: Angkasa.

Light, D., Keller, S., \& Calhoun, C. 1989. Sociology. New York: Alfred A. Knopf.

Macionis, J. J. 1970. Society the basics. New Jersey: Prentice Hall, Englewood Cliffs.

Muhaimin, A. 1991. Pemikiran Pendidikan Islam. Bandung: Bumi Aksara

Mulyana, R. 2004. Mengartikulasikan Pendidikan Nilai. Bandung: Alfabeta

Munawwir, A. 1984. Al-Munawwir; Kamus Arab-Indonesia. Yogyakarta: Unit Pengadaan Buku-buku Ilmiah Keagamaan Pondok Pesantren al-Munawwir.

Nasution, H. 1996. Islam Rasional, Gagasan dan Pemikiran. Jakarta: Mizan 
Penanaman Nilai-Nilai Islam Berupa Integritas al-Qur'an dalam Pengajaran Ilmu Kauniyah Melalui RPP

Amaliah Nurjannah

Nuris, A. 2005. Klasifikasi dan Hierarki Ilmu: Posisi Logika dalam al-Ulum al-Kauniyah dan alUlum at-Tanziliyah. Tersedia: http://jendelahatiq.blogspot.co.id/2011/10/klasifikasidan-hierarki-ilmu-posisi.html. Diakses pada tanggal 1 Oktober 2015.

Sumaatmadja, N. 2005. Konsep Dasar IPS. Jakarta: Pusat Penerbitan Universitas Terbuka

Tim Penyusun Kamus Pusat Pembinaan dan Pengembangan Bahasa. 1998. Kamus Besar Bahasa Indonesia. Jakarta: Depdikbud RI Balai Pustaka

Universitas Gunadarma. Modul Filsafat Ilmu. Tersedia: http://elearning.gunadarma.ac.id/docmodul/filsafat ilmu/bab4-apa itu ilmu.pdf. Diakses pada tanggal 1 Oktober 2015.

UPI. Tanpa tahun. Ilmu Pengetahuan dalam Islam. Tersedia: file.upi.edu/Direktori/FPBS/JUR._PEND...PAI.../BAB_XII.pdf. Diakses pada tanggal 1 Oktober 2015

Zulkarnain. (2008). Transformasi nilai-nilai pendidikan Islam, manajemen berori-entasi link and match. Yogyakarta: Pustaka Pelajar 